\title{
Demand Response Programs Significance, Challenges and Worldwide Scope in Maintaining Power System Stability
}

\author{
Muhammad Faizan Tahir, Chen Haoyong ${ }^{*}$, IEEE \\ Senior Member, Idris Ibn Idris, Nauman Ali Larik \\ School of Electric Power, South China University of \\ Technology, Guangzhou, P.R. China
}

\author{
Saif ullah Adnan \\ School of Electronics and Information Engineering, South \\ China University of Technology, \\ Guangzhou, P.R. China
}

\begin{abstract}
In order to cope up the continuously increasing electric demand, Governments are forced to invest on Renewable Energy (RE) sources due to scarcity of fossil fuels (such as coal, gas and oil), high costs associated with it and emission of greenhouse gases. However, stochastic nature of RE sources like wind and PV threaten the reliability and stability of power system. Demand Response (DR) is an alternative solution to address the issues of economic constraints, integration challenges of RE, and dependency on fossil fuels. It is an aspect of Demand Side Management (DSM) that converts consumer's passive role to active by changing energy consumption pattern to reduce peak load. DR plays the role in deferring the investment on building new power plants, eliminating transmission losses and making the society green. This work analyzes initialization of different DR programs due to slumping technology costs and recognition of users' behavior in electricity market. Moreover, this paper points out the problems associated with DR and its project implementation across USA, China and developed cities of Europe.
\end{abstract}

Keywords-Demand side management (DSM); demand response (DR); renewable energy $(R E)$; DR programs; wind; $P V$

\section{INTRODUCTION}

DSM also known as energy demand management was first coined in 1973 due to high prices of fuel and energy crisis [1], [2]. It was first premised by Electric Power Institute in 1980s. It is the process of implementing, planning, monitoring and controlling user end activities to match the balance between supply and demand [3], [4].

Other than increasing power generation to meet up the increase load, demand can be controlled at user end by demand response, energy efficiency and load conservation techniques. Peak reduction, shifting peak load to valley hours and turning on users own generating units are popular DR techniques and these techniques helps in deferring the installation of new power plant, decreasing peak demand and improving the load factor. In addition, Energy Efficiency (EE) methods encourages the customer to use energy efficient devices that consume less power such as Compact Fluorescent (CFL) lights. Strategic load conservation ideas like building home in such a way that it requires less cooling during summer and less heat during winter play the vital role in reducing electric demand at user end [5]-[7]. However, strategic load growth like electrification increases the energy consumption but its objective is to increase electricity sale and local resource consumption to find the alternate of fuel. Flexible load curve gives the option that load can be interrupted by grid operators when needed to reduce peak demand but varying reliability and quality of service. All these DSM techniques not only serve to reduce power consumption but also put its effort in building green society [8]-[10].

Making the society green requires the abundant use of RE sources such as PV and wind. However, integration of these stochastic sources threatens the grid reliability. Consequently, DR proves to be effective alternate to supply reserves, reducing peak and providing other ancillary services to mitigate the integration challenges. Increasing trend of RE generation till 2017 and DSM classification are shown in Fig. 1 and 2, respectively.

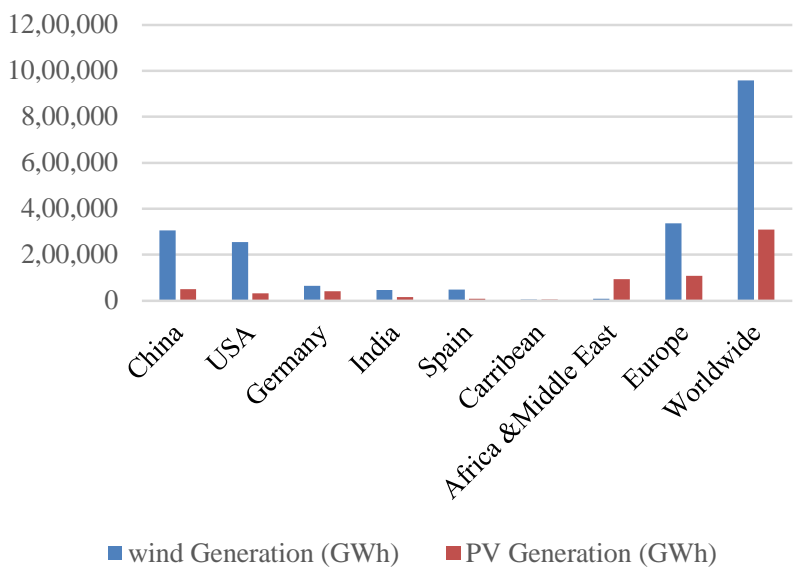

Fig. 1. PV and wind generation (GWh) till 2017. 


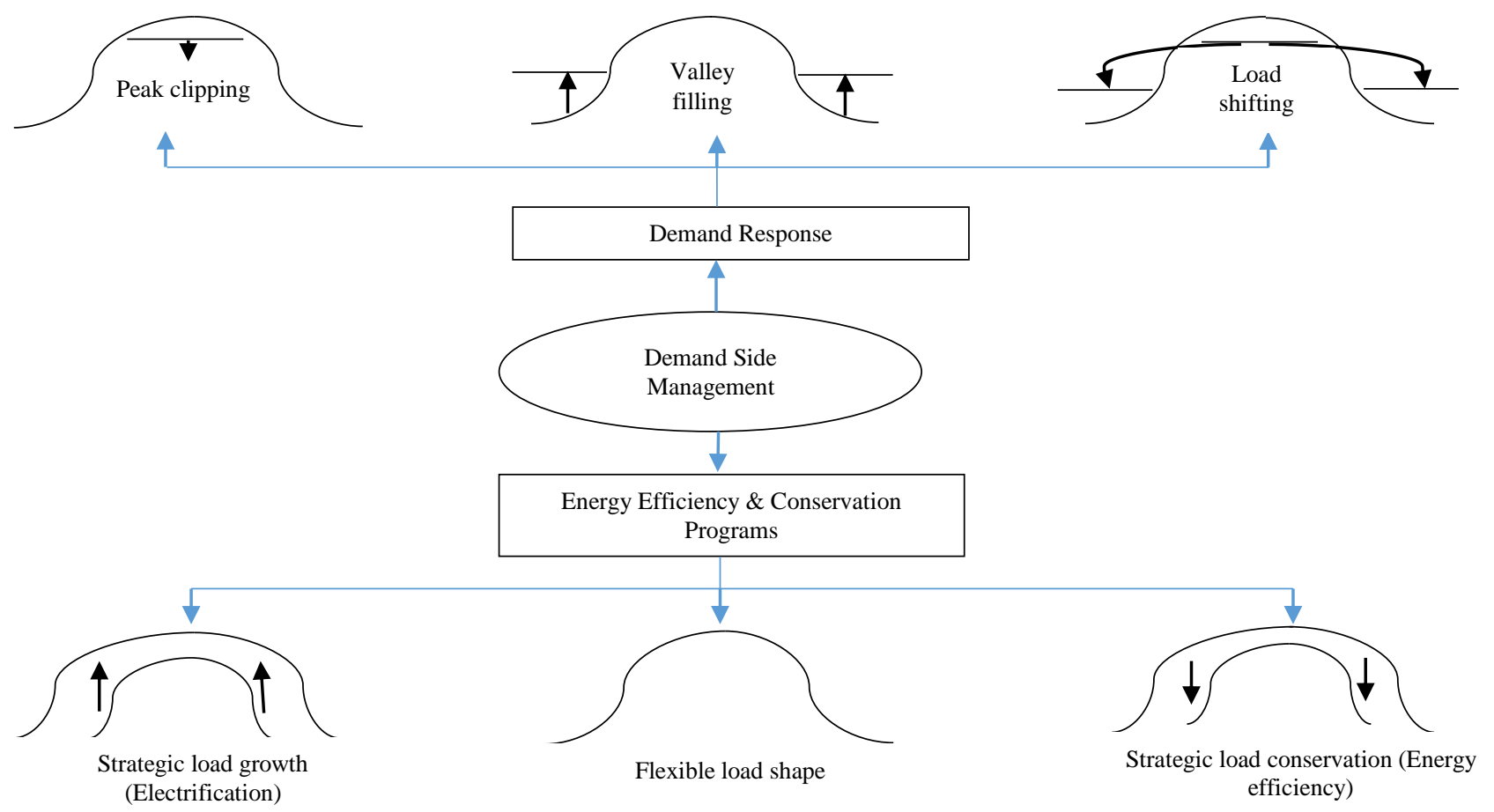

Fig. 2. Classification of DSM explaining load shaping techniques.

\section{A. Need of Demand Response}

With each passing year the power consumption of residential, commercial and industrial users is increasing exponentially. It has been estimated that till 2030 power demand will be increased up to 40 percent. In order to overcome this problem the first solution come in mind is to generate more power. Amount of power generation can be increased by installing more small, medium or large size power plants in proportion with the increase in demand. More fossil fuels generating units will be required which will produce greenhouse gases and pollute the environment that is already suffering with extreme global warming issues [11]. Furthermore, after power generation, distribution and transmission networks need to expand. These all set ups from generation to transmission to distribution not only increases the cost but also increases the occurrence of unwanted events like brown outs or black outs [12]. Our present grid system are prone to faults and often suffer with problem of brown outs when load increases beyond the peak load. Third world countries that do not have enough sources to catch up the demand often have to shed the load. In case of failure of shedding proper amount of load power system leads to cascaded failure that causes the whole grid to black out [13]. Number of cases of these black outs has been increased significantly since past few years that effected millions of consumers.

The effective and less costly solution other than firing up the generating plants is to control or reduce the demand. There have been few hours in a day where demand shoots up and this time period is known as peak hours or peak period. During these peak hours if consumer shifts their load to off peak hours or reduce their energy consumption by using devices that consume less power: system will not suffer the problem of reliability. Moreover the need to build new generating plants will be reduced that will save a lot of capital cost. In order to achieve this, continuous monitoring of power consumption should be noted that needs two way communication between utility operators and consumers. The different possibilities of coping up increase in demand are shown in Fig. 3:

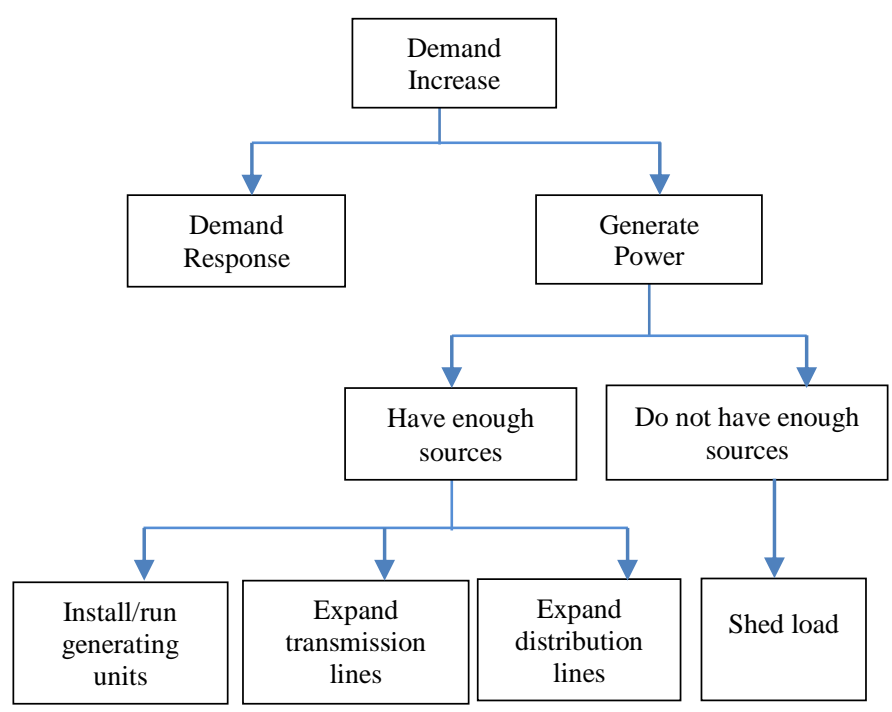

Fig. 3. Different schemes to meet the increase demand.

The popular method of reducing load from 1970s to $1990 \mathrm{~s}$ was curtailable and interruptible programs but customers were never exposed to real-time whole price signals. Integration of more renewable energy sources in the electric grid causes uncertainty in electric supply [14], [15]. This forces the utility managers to work on demand response programs that base on price response in order to convince customers to participate in 
these programs. Rest of the paper is organized as follows: Sections 2 and 3 enlist customers load reduction methods and DR programs respectively while Section 4 elaborates DR measurement phenomena by calculating self and cross elasticities. Section 5 elaborates the merits and demerits of DR schemes. Section 6 analyze the DR significance across USA, Europe and China and also identify technical barriers to implement these programs. Section 7 concludes the paper and also discusses the future work.

\section{Customers LOAD Reduction Methods}

DR can be done at three levels.

\section{A. Residential level}

B. Commercial level

C. Industrial level

There are three ways of reducing the load for residential customers during peak hours [15], [16].

- First one is to completely shed the load during peak hours when price is considerably high but it will involve the loss of comfort. Turning off the AC, heaters, dryers or other household appliances during these hours helps to reduce peak demand.

- Second one is not to shut the high consuming devices but reduce its consumption level such as turning on the $\mathrm{AC}$ at 26 or 27 instead of 18 will reduce the electricity consumption.
- Third option is to shift load to off peak hours. Daily house hold activities like washing clothes, dryers and cooking chores can be shifted from afternoon or evening to night when power consumption is relatively less.

Prior to save electricity and reduce the monthly bill; residential customers also receive special incentives from electric suppliers in participating demand management.

Unlike residential customers it is difficult for industrial customers to shed load completely. This entails commercial customers to reduce load and provide stability to power system when demand increases. Demand can be mitigated considerably without being effected too much by just dimming the lights of lobby of big hotel for 20 minutes or changing the thermostat setting of freezers of big plazas.

The best way for industrial users are to shift load on their own power generating units because industry will not able to bear the loss of shutting or reducing the load. These two customers can save electricity costs by DR and can earn back as much as 5 to $25 \%$. Prior to the customers benefit to opt DR programs, utilities also has their reasons in convincing customers to participate in these programs [17].

\section{DEMAND RESPONSE PROGRAMS}

There are many demand response programs [18]-[22] and its types and sub types are shown in Fig. 4.

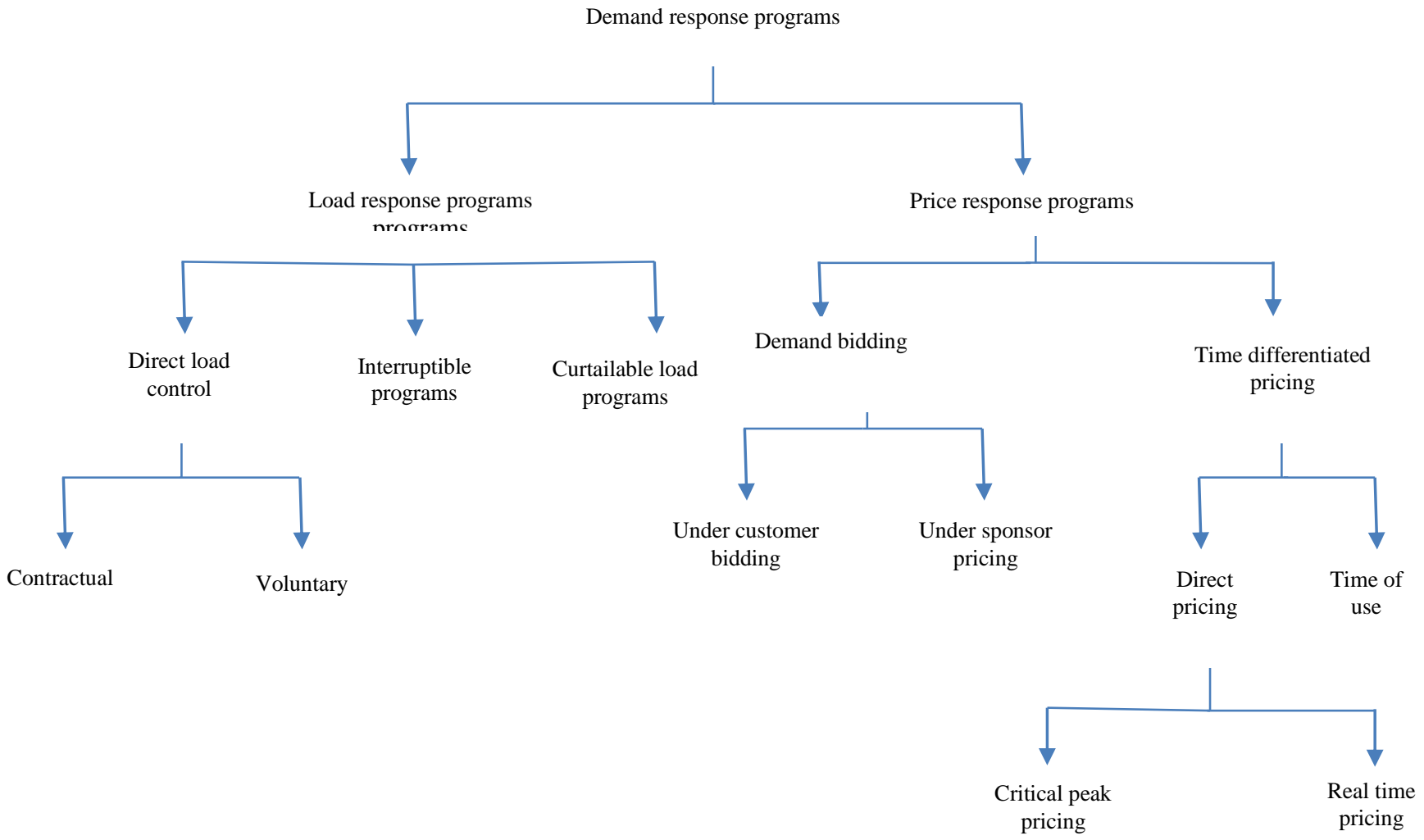

Fig. 4. Different schemes to meet the increase demand. 


\section{A. Load Response Programs}

This type of demand response also called event based program, reliability based or dispatchable. In this kind of program, some agreement takes place between customers and utility. Some incentive or reduction in bills are offered to customers by reducing load when utility asked them to do so. Grid operators install some control technologies in consumer's premises to control and monitor their electricity usage. This load response program can be referred as contractual and voluntary load programs.

- According to contractual load programs agreement customers must curtail their load during peak hours and receive guaranteed payment otherwise being penalized.

- However, in voluntary programs agreement customer decides by himself when and when not to reduce or shed the load.

This kind of incentive based scheme sometimes also known as explicit demand response.

1) Direct load control: As the name indicates in direct load control program utility directly control the customer's energy consumption. Grid operators install some remote control devices such as wireless communication, wired communication, radio control, GSM control and so on. With the help of these devices they can remotely monitor and control the consumer's appliances. Mostly this type of program is suitable for residential customers.

2) Interruptible programs: This type of demand response mostly targets big commercial and industrial customers. These customers can shut down electricity for short time interval or can switch back to their own generating units. Participating in this program customers receive electricity rates that are much lower than industrial rates and these rates are usually known as "interruptible rates".

3) Curtailable load programs: Those customers that cannot shut their supply can participate in DR programs by just reducing their load and this type of program is known as curtailable load programs. Mostly industrial and commercial customers signed to this program and they are generally notified about shedding the load between 30 minutes to two hours.

\section{B. Price Response Programs}

Price response program also known as market-based, nondispatchable or non-event based programs is totally based on voluntary action of customers. Showing willingness to take part in this program customers are offered some economic incentive or pricing choice. Generally, this scheme focuses in reducing the wholesale market price.

This price based voluntary scheme also refers as implicit demand response.

1) Demand bidding programs: Demand bidding or buyback programs that sometimes also known as economic response programs mostly targets commercial and industrial facilities. These customers can minimum shed load of $100 \mathrm{~kW}$ per event. This program further divides in two branches depending upon how bid is structured.

\section{a) Under Customer Bidding}

In this case, customers bids the price that is lower than market price for reducing specific load at specific time at most a day ahead or in some cases an hour ahead.

\section{b) Under Sponsor Pricing}

In this scheme, Customers are being notified the price of per $\mathrm{kWh}$ of load reduction by the market administrators. Upon showing willingness to this method customers receive reduced electricity price depending on how much reduction in load occurs.

2) Time differentiated pricing: Electricity suppliers expose customers to time-varying electricity prices that show the price of electricity at different time periods. It may vary from flat day and night price to high dynamic price depending on hourly wholesale prices. Therefore customers can shift load from high prices intervals to low prices intervals.

Electricity price does not remain constant; it varies significantly according to months of the year, days of the week and hours of the day. During peak periods the market prices are considerably high as compared to off peak periods. There are several structures for this scheme that are mentioned below:

\section{a) Time-of-Use Rates}

Time-of-use rates do not follow the single flat rate for energy consumption instead prices are high when electric demand is higher. Usually in summer period, afternoon 6 hours are considered as peak hours while remaining other hours are considered off peak hours. TOU is applied to these two blocks of hours where price is predetermined and remains constant. This program gives consumers chance to reduce electricity bill by shifting load from peak hours to mid peak hours or valley hours.

\section{b) Dynamic Pricing}

In contrast to TOU rates in which electric suppliers gave forecast of load a day ahead but in dynamic pricing it is as closely correlated as one or two hours ahead. It reflects hourly variation of wholesale market prices. Increasing trend of smart grids that includes smart meters, advanced communication and control technologies creates novel options for dynamic rate structures. The possible dynamic pricing mechanisms are mentioned below.

\section{c) Real Time Pricing}

Electricity prices not only vary weekly or daily, but also vary hourly or sub hourly. Real time pricing (RTP) reflects the prices that varies on hourly basis. It informs customers of price variation as little as of 5 minute interval.

\section{d) 5.2.4 Critical Peak Pricing}

Critical peak pricing (CPP) is a hybrid of TOU and RTP. TOU has two main standard periods on and off periods but CPP adds the third block called "critical peak period." TOU blocks have fixed price and specific time frame unlike CPP block that may or may not occur on any specific day. 
This program may come in account during emergency condition in power system or when electric suppliers anticipate high wholesale electric prices. In these cases grid operators might invoke critical events during any specific time interval such as it can be from 6 p.m. to 10 p.m. on any cold day of a winter or between $3 \mathrm{pm}$ to $6 \mathrm{pm}$ of summer afternoon. During this critical time interval electricity prices will shoot up exponentially.

\section{DEMAND RESPONSE MEASUREMENT}

Amount of peak reduction is an indicator for the success of DR. Besides peak reduction dynamic pricing act as an important factor to determine sensitivity of electric users to price of electricity. Users sensitivity is determined by demand price elasticity which is outlined as ratio of change in demand to ratio of change in price and is calculated as [23]:

$$
\begin{aligned}
& E=\frac{\frac{\partial d(i)}{d(i)}}{\frac{\partial p(j)}{p(j)}}=\frac{\partial d(i)}{d(i)} * \frac{p(j)}{\partial p(j)}=\frac{p(j)}{d(i)} * \frac{\partial d(i)}{\partial p(j)} \\
& \mathrm{E}=\text { elasticity of demand } \\
& \partial \mathrm{d}(\mathrm{i})=\text { Change in demand }(\mathrm{MWHr}) \\
& \mathrm{d}(\mathrm{i})=\text { Initial demand }(\mathrm{MWHr}) \\
& \partial \mathrm{p}(\mathrm{j})=\text { Change in price }(\$ \text { or } \mathrm{RMB} / \mathrm{MWHr}) \\
& \mathrm{p}(\mathrm{j})=\text { Initial price }(\$ \text { or } \mathrm{RMB} / \mathrm{MWHr})
\end{aligned}
$$

Highly elastic demand occurs when huge changes in demand results only slight changes in prices. Price demand elasticities can be divided in two types counting on users' response to price demand elasticities:

\section{A. Self-Elasticity/Single Period Elasticity}

Loads like incandescent lamps that can only be turned on and off and cannot be shifted to some other period has sensitivity during a single period only and known self-elasticity or single period elasticity and always has negative value [24].
Therefore, single period elasticity is defined as ratio of relative change in demand during $t_{\text {th }}$ hour to relative change in its dayahead price during same hour. It can be calculated as:

$$
E(i, j)=\frac{p_{o}(j)}{d_{o}(i)} * \frac{\partial d(i)}{\partial p(j)}
$$

or can be expressed as:

$$
E^{t k}=\frac{p_{o}{ }^{t}}{d_{o}{ }^{t}} * \frac{\partial d_{d}{ }^{t}}{\partial p_{d}{ }^{t}}
$$

$p_{o}(j)$ or $p_{o}{ }^{t}=$ change in price during $t_{t h}$ hour

$\mathrm{d}_{\mathrm{o}}(\mathrm{i})$ or $\mathrm{d}_{\mathrm{o}}{ }^{\mathrm{t}}=$ initial demand during $\mathrm{t}_{\mathrm{th}}$ hour

\section{B. Cross-Elasticity/Multi Period Elasticity}

Loads like processing loads that has the ability to operate in more than one mode and can switch its mode to off peak periods has cross elasticity or multi period elasticity [23], [25]. Consequently, cross-elasticity is termed as ratio of relative change in demand during $t_{t h}$ hour to relative change in its dayahead price during kth hour and its value is always positive.

$$
\begin{aligned}
& E^{t k}=\frac{p_{o}{ }^{k}}{d_{o}{ }^{k}} * \frac{\partial d_{d}{ }^{t}}{\partial p_{d}{ }^{t}} \\
& \mathrm{p}_{\mathrm{o}}{ }^{\mathrm{k}}=\text { change in price during kth hour } \\
& \mathrm{d}_{\mathrm{o}}{ }^{\mathrm{k}}=\text { initial demand during kth hour }
\end{aligned}
$$

It reveals that DR schemes performance are comprised of below factors.

\section{1) Peak demand reduction \\ 2) Demand elasticity}

DR can work efficiently only when automated response technologies are enabled. The complete architecture of these technologies is shown in Fig. 5.

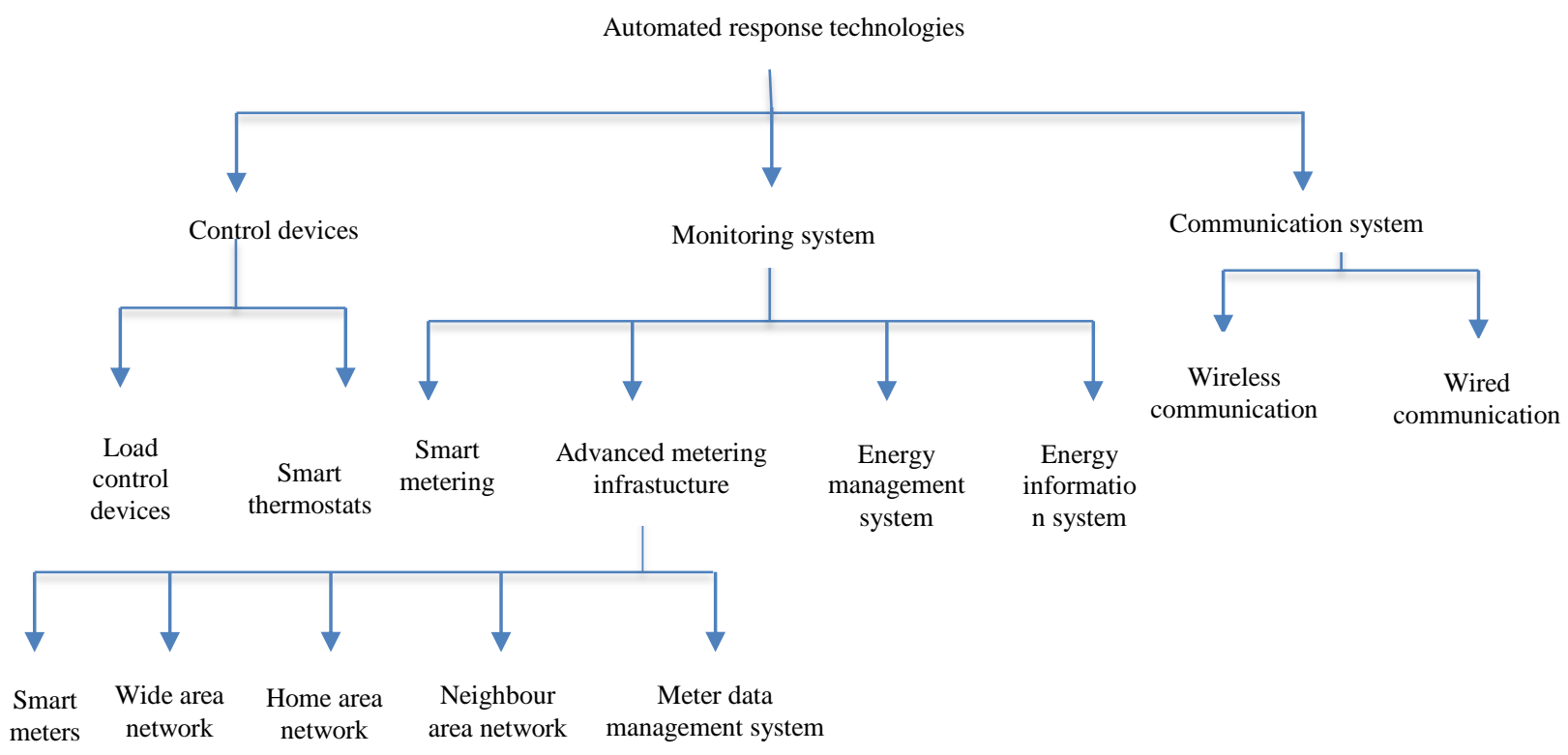

Fig. 5. Automated technologies needed to implement DR. 


\section{MERITS AND DEMERITS OF DEMAND RESPONSE}

Electric power system has three main features:

1) Electric energy cannot be stored economically for that demand and supply must be in balance all the time.

2) Due to the need of increase in power generation because of the continuous increase in demand, grid conditions change drastically from day to day or even hour to hour. It may cause the mismatch between supply and demand that will jeopardize the stability of system.

3) Electric grid that includes power generating units, hundreds of kilometers long transmission lines network and distribution network makes it highly capital-incentive.

These problems enhance the importance of demand response. Merits of DR can be viewed as power grid and electric customer benefits which are discussed below.

\section{A. Power Grid Benefits}

Prior to the customers benefit to opt DR programs, utilities also have their reasons in convincing customers to participate in these programs. In case of sudden increase in demand power system has to use their stand by generating units such as hot spinning reserve and cold spinning reserve. First, hot spinning reserves comes in action and if it is not sufficient to fulfill the demand then has to start the cold spinning reserves as well.

This all can be avoided just by opting to DR programs. These programs can eliminate the need of building new power plants such as in New York alone industrial and commercial customers save up to $543 \mathrm{MW}$ that is about the capacity of medium size power plants.

- Increase in demand during peak period forces to run the standby generating units that may only run few hours in the entire year. This problem can be dealt easily by reducing peak demand during these hours.

- DR eliminates the problem of integration of renewable energy sources to the grid. The grid uncertainty also increased drastically due to the varying nature of these sources.

- During sudden increase in load causes the frequency to decay and if generation does not match up with load, it will cause the generators to shut down. This problem can lead to cascaded failure and whole system will suffer black out. Demand response can become important to eliminate this problem and keep the balance between demand and supply.

- Governor that control the amount of fuel in generators come in action as soon as demand increase. In case governor action is not sufficient to fulfill the load requirement power system has to switch to hot spinning reserve and then to cold spinning reserves. There will be no need of these ancillary services by following the demand response programs.

- After getting awareness of market price (by following price response program) if customers reduce or shift load, it will lower the wholesale market prices. In this scenario customers not only save bill but also help other customers in reducing their bill as well. These advantages are summarized in Fig. 6.

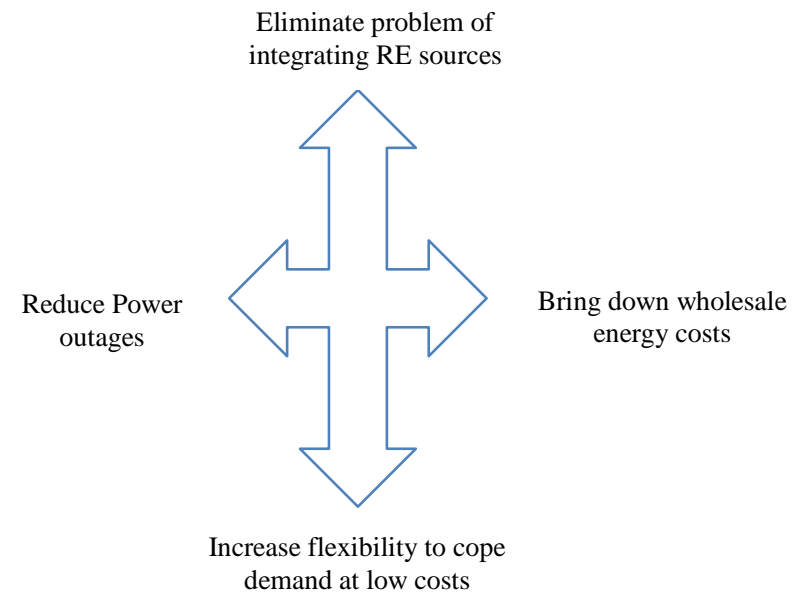

Fig. 6. Power grid benefits.

\section{B. Electric Customer Benefits}

- Customers can reduce electricity bill by shutting down high load devices during peak periods.

- Number of increasing fossil fuels generating units has adverse effect on climate because of the release of greenhouse gases. Demand response helps to make the environment cleaner and healthier.

- Customers can continuously monitor consumption and prior to their own financial management can also play the role towards grid stability that reflects the positive impact on society as depicted in Fig. 7.

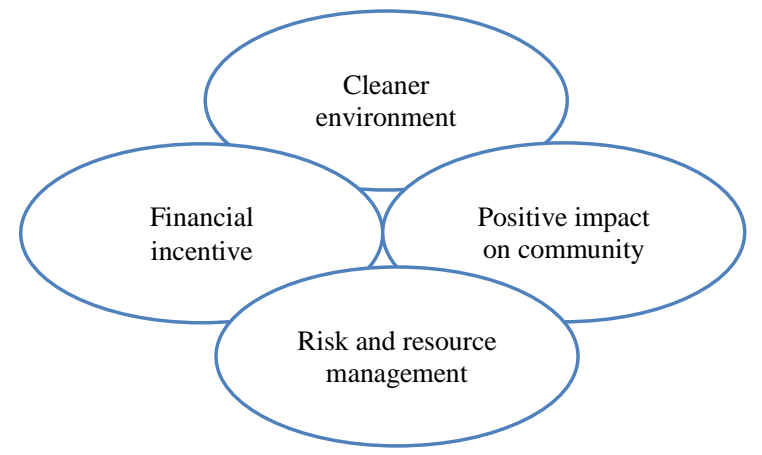

Fig. 7. Electric customer benefits.

As DR programs are gaining importance by each passing day but still there are number of problems and demerits associated with it are discussed below:

- Demand response programs need two way communication that will require some changes in current electric grid. Control, monitoring and communication devices will increase the initial cost of the utility.

- The first and foremost thing for demand response is the participation of customers. Sometimes customers are 
hesitate to take part and think these programs will benefit only utility. Furthermore, they don't want to waste time to monitor and control the load.

- The current market structures lack the appropriate market mechanism. Beforehand planning for DR causes doubt in the response that can be accomplished in real time.

- Smart meters and smart thermostats are needed to install at residential customers' premises to participate in DR programs. Customers feel reluctant to share their privacy and control to utility. Furthermore they got confused that in spite of reducing the same amount of load why the price of electricity varies on daily basis?

- DR programs focuses more on commercial and industrial consumers instead of residential because of the high success and income involved with these customers.

- Few energy sellers are reluctant to participate in DR activities because it will reduce the sale of energy efficient devices.

- Monetary funds of DR programs are beyond the customers controls. Policies of contracts and incentives for DR programs may vary year to year or might eliminate it. These little uncertainties causes customers observe DR as not a "sure bet."

\section{WORLD WIDE DEMAND RESPONSE EXPERIENCE}

\section{A. DR in USA}

The invention of Air conditioning system by a New York student Willis Carrier in early 20th century turned in to central heating/cooling unit till 1970s. This central air conditioning cause the electricity demand to grow and load factor to decline.
Simultaneously, oil crises and scarcity of natural gas increases the electricity price. Ultimately in 1980s oil prices collapsed and natural gas used to address the price of new capacity [26], [27]. These scenarios and "integrated resource planning" force the USA energy policy makers to work on load management and during 1980s and 1990s interruptible DR programs quiet become popular. 1992 Energy Policy Act of USA allowed independent power producer to participate in market price mechanism [28] that encourages to invest heavily on DR programs that reach up to 2.7 billion dollar nationwide in 1993 . However, this value declined to half (1.3 billion dollar) till 2003 due to industry restructuring. Merely 22,904 MW peak load reduced in 2003 due to DSM activities.

Restructuring of USA electric power system during 1990s unbundled generation, transmission and distribution network. Transmission operations in many regions have evolved into Regional Transmission Organizations (RTOs) under the supervision of the Federal Energy Regulatory Commission (FERC) that manage transmission systems as well as wholesale power markets. Therefore, same restructuring or deregulation that swept during 1990s used as a mean to promote DSM activities by developing competitive market price and announcing "public benefit programs" [20].

In 2008, 38,000 MW and $2700 \mathrm{MW}$ peak load reduction caused by incentive and price based DR programs respectively. Contribution of DR towards reducing load in 2010 reach up to 31,702 MW. Installation of Advanced Metering Infrastructure (AMI) has increased from $8.7 \%$ to $23 \%$ [29] within three years span (2010-2012) and the number reaches to 38 million in 2012 [30]. This number continues to grow up to 65 million in 2015 and furthermore increased integration of distributed generation push to maximize DR potential. FERC estimated that by the year 2019, amount of load reduction by DR may reach up to 138,000 MW that makes 14 percent peak demand of total load and its details are listed in Table I.

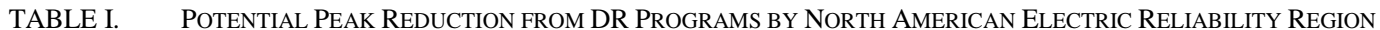

\begin{tabular}{|l|l|l|l|l|}
\hline \multirow{2}{*}{ RTO/ISO } & \multicolumn{2}{|c|}{2013} & 2014 \\
\cline { 2 - 5 } & $\begin{array}{l}\text { Peak reduction } \\
\text { (MW) }\end{array}$ & $\begin{array}{l}\text { Percent of peak } \\
\text { demand }\end{array}$ & $\begin{array}{l}\text { Peak reduction } \\
\text { (MW) }\end{array}$ & Percent of peak demand \\
\hline California (CAISO) & 2180 & $4.8 \%$ & 2316 & $5.1 \%$ \\
\hline Electric Reliability Council of Texas (ERCOT) & 1950 & $2.9 \%$ & 2100 & $3.2 \%$ \\
\hline ISO New England, Inc. (ISO-NE) & 2100 & $7.7 \%$ & 2487 & $10.2 \%$ \\
\hline Midcontinent Independent System Operator (MISO) & 9797 & $10.2 \%$ & 1211 & $9.0 \%$ \\
\hline New York Independent System Operator & 1307 & $3.8 \%$ & 10416 & $4.1 \%$ \\
\hline PJM Interconnection, LLC (PJM) & 9901 & $6.3 \%$ & 48 & $7.4 \%$ \\
\hline Southwest Power Pool, Inc. (SPP) & 1563 & 28798 & $6.1 \%$ & 28934 \\
\hline Total ISO/RTO & $3.5 \%$ & $0.1 \%$ \\
\hline
\end{tabular}


TABLE II. PEAK REDUCTION OF DIFFFERENT DR SCHEMES

\begin{tabular}{|l|l|l|}
\hline Sr. No: & DR Program & Peak Reduction (\%) \\
\hline 1 & Capacity Resource & 29 \\
\hline 2 & Interruptible load & 24 \\
\hline 3 & Direct load control & 15 \\
\hline 4 & Time of use & 12 \\
\hline
\end{tabular}

DR in USA can be considered a source of generation as it covers $10 \%$ demand of country. Moreover, USA is interested in promoting more of DR programs in next 5 years as only 4 types of DR schemes contributes to $80 \%$ of peak reduction as shown in Table II.

DR offers a win-win situation both for participants and utility and is expected to become more mainstream as it saves money, reduce the need to build more power plants and reduce the $\mathrm{CO}_{2}$ emission to protect the environment. The total peak reduction by following DR and EE techniques during 19922008 are summarized in Fig. 8.

\section{Total peak reduction (MW)}

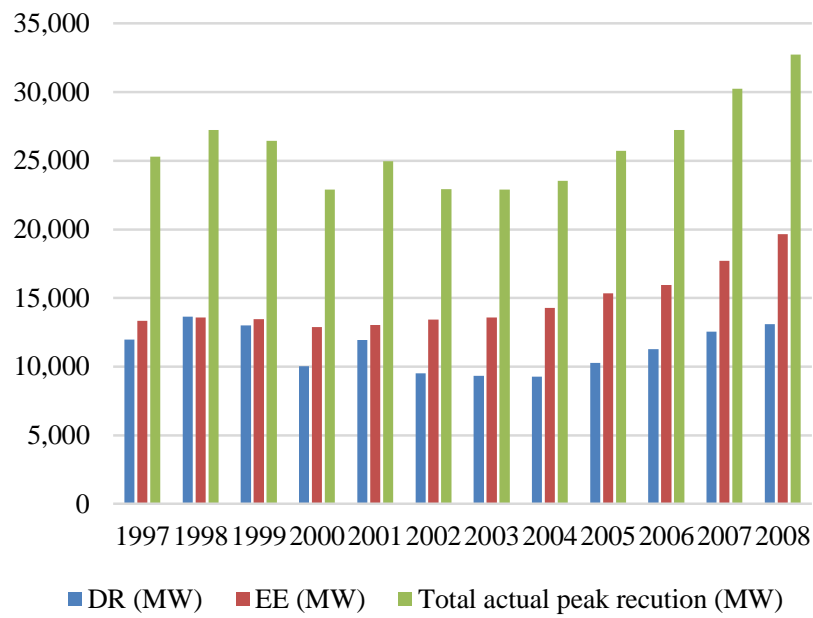

Fig. 8. Total peak reduction during 1997-2008.

\section{B. DR in Europe}

Unlike USA, summer peak periods are not a major concern in Europe. Though, during winter heating load increases electric demand but the bigger drivers are the increasing share of renewable energy such as wind and solar power. Large part of USA load management is via capacity markets but Europe has just initiated to develop the structures that allow DR resources to participate effectively [31].

Since past 20 years, electric demand reduction in Europe has been done by different forms of load shedding mechanisms [32]. These techniques did not base on precise price signals to give the dynamic pricing option to customers. In 2008, Union for the Co-ordination of Transmission of Electricity (UCTE) estimated DR forecasts in European countries that is shown in Table III. Except Germany and Hungary, DR potential continues to rise and up to 2015 and UCTE forecast has accomplished desire goal [32].
TABLE III. DR FORECASTS TILL 2020

\begin{tabular}{|l|l|l|l|l|l|}
\hline \multicolumn{7}{|l|}{ Year wise DR forecast (GW) } \\
\hline Country & $\mathbf{2 0 0 8}$ & $\mathbf{2 0 1 0}$ & $\mathbf{2 0 1 3}$ & $\mathbf{2 0 1 5}$ & $\mathbf{2 0 2 0}$ \\
\hline Italy & 4.00 & 4.00 & 4.00 & 4.00 & 4.00 \\
\hline France & 3.60 & 3.00 & 3.00 & 3.00 & 3.00 \\
\hline Spain & 2.00 & 2.30 & 2.50 & 2.70 & 3.00 \\
\hline Netherland & 1.00 & 1.00 & 1.10 & 1.25 & 1.50 \\
\hline Greece & 0.40 & 0.60 & 0.80 & 1.00 & 1.30 \\
\hline Germany & 0.20 & 0.30 & 0.40 & 0.50 & 0.05 \\
\hline Belgium & 0.20 & 0.20 & 0.20 & 0.20 & 0.20 \\
\hline Hungary & 0.00 & 0.05 & 0.08 & 0.10 & 0.20 \\
\hline Monte negro & 0.03 & 0.03 & 0.05 & 0.05 & 0.05 \\
\hline Luxemburg & 0.02 & 0.02 & 0.02 & 0.02 & 0.02 \\
\hline UCTE countries & 11.45 & 11.50 & 12.15 & 12.82 & 13.32 \\
\hline
\end{tabular}

The most positive step towards consumer participation was the inclusion of DR in Network codes during 2014-2015. Network codes are the list of rules blueprinted by European network of transmission system operators for electricity (ENTSO-E) to facilitate integration and efficiency of European electricity market and its objective till 2020 is [33], [34].

- Reduce $40 \%$ greenhouse gas emission in comparison to 1990

- $20 \%$ involvement of RE consumption

- $27 \%$ energy saving

Summary of DR potential till to date is shown in Fig. 9:

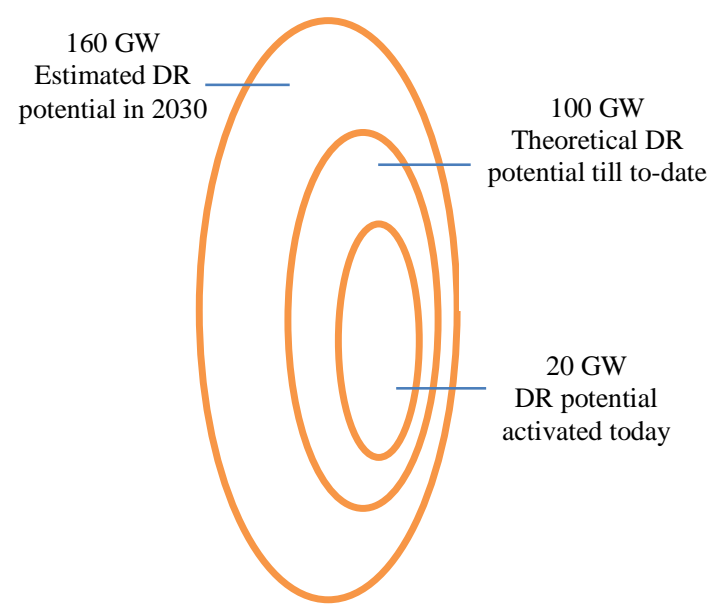

Fig. 9. DR potential in Europe.

Recently, potential of electric demand response, integration of renewable energy to match the balance between supply and demand has been discussed by Industry Research and Energy Committee (ITRE) held on 30th May 2017. Vice Chairman of the committee address the problem of continuously increasing load and said "electricity generation follows consumption" paradigm is no longer applicable [35]. This phrase emphasizes the importance of DR in addressing this critical issue across the whole Europe. Peak reduction by different companies across few developed European countries and list of technical and policy barriers in implementing DR across various countries are shown in Table IV and Fig. 10. 
TABLE IV. DR FORECASTS TILL 2020

\begin{tabular}{|c|c|}
\hline Country & Restrictions/Barriers in implementing DR \\
\hline Austria & $\begin{array}{l}\text { EMC (Electricity Market Code) assign strict requirements for } \\
\text { participating in DR programs. }\end{array}$ \\
\hline Germany & No penalties against producing a negative reserve \\
\hline Denmark & $\begin{array}{l}\text { Involvement of DR activities is unclear on balancing } \\
\text { markets. }\end{array}$ \\
\hline Finland & Participation for primary reserve is limited. \\
\hline France & $\begin{array}{l}\text { Aggregators can bid separately but unable to bid as one } \\
\text { single block }\end{array}$ \\
\hline Ireland & Ancillary services not available for DR activities. \\
\hline Sweden & DR aggregators cannot participate independently in market. \\
\hline Poland & $\begin{array}{l}\text { DR programs are limited to only Emergency demand side } \\
\text { reserve program. }\end{array}$ \\
\hline Spain & Only interruptible load program is available. \\
\hline Italy & $\begin{array}{l}\text { Interruptible load program is available only for industrial } \\
\text { loads. }\end{array}$ \\
\hline
\end{tabular}

Potential of DR around 15\% of peak around

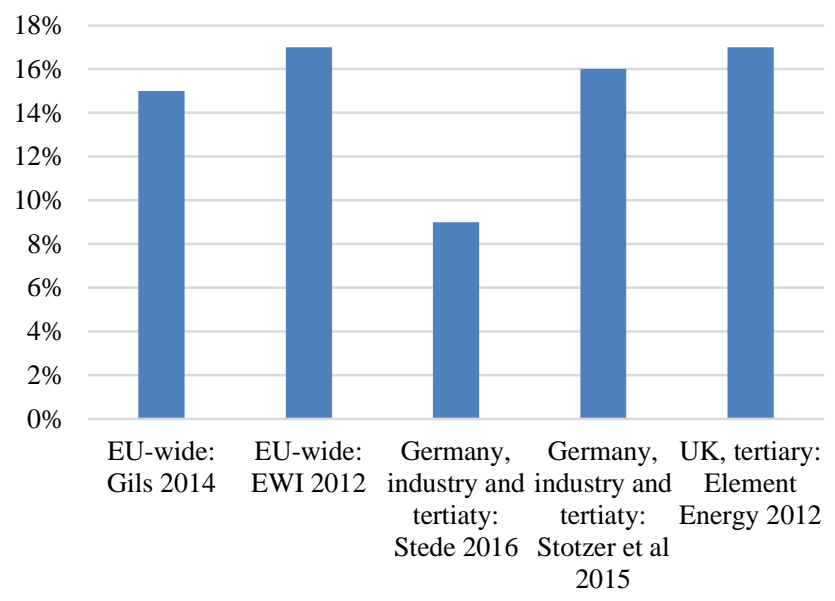

Fig. 10. Peak reduction by DR schemes across Europe.

Therefore, fostering DR is an effective way to meet the energy goals of Europe without increasing the GHG emission gases. Energy goals of Europe to use more RE and decarbonize the environment till 2030 are elaborated in Fig. 11.

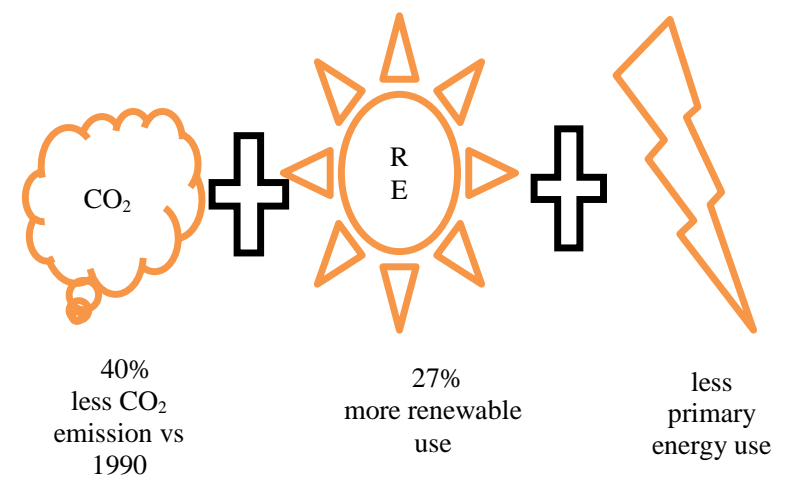

Fig. 11. Europe energy goals till 2030.

\section{DR in China}

China represents $44 \%$ of total world coal production and $65 \%$ of its power demand is fulfilled by these fossil fuel sources [36] as it is world's largest electricity producer and consumer. Load management started in 1990s in china but load shedding and black outs issues due to increase load during 2003-2008 fasten the implementation of DSM projects especially DR programs [37]. DR programs enlisted in Table V are actively working in China.

TABLE V. ACTIVE DR PROGRAMS IN CHINA

\begin{tabular}{|l|l|l|}
\hline $\begin{array}{l}\text { Price-based } \\
\text { program }\end{array}$ & Incentive-based program & $\begin{array}{l}\text { Policy-guided } \\
\text { program }\end{array}$ \\
\hline Time-of-use rates & Interruptible/curtailable load & Power rationing \\
\hline $\begin{array}{l}\text { Critical peak } \\
\text { pricing (CPP) }\end{array}$ & Direct load Control & Orderly power \\
\hline Two-part pricing & & \\
\hline
\end{tabular}

Jiangsu is the first province that issue its own DSM regulations in April, 2002 [38]. Up till 2003, it used TOU scheme for industrial customers to implement DR and about 95\% of users enrolled in it. Nanjing, Yangzhou and Xuzhou are the cities that actively participated in DR events. Complete list of peak reduction in different provinces during 2003 are presented in Fig. 12.

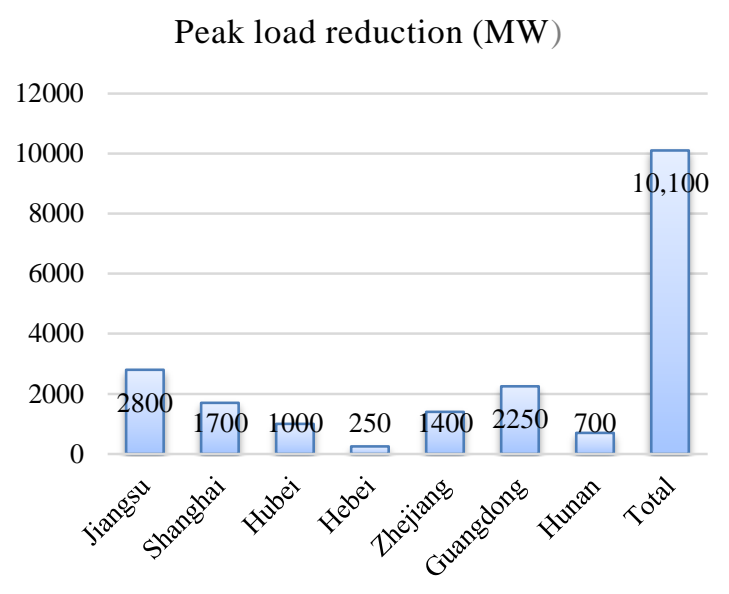

Fig. 12. Peak reduction in pilot cities during 2003.

10 GW increase in load in Foshan city (Guangdong province) in 2014 prompt to follow DR schemes and resulted in $450 \mathrm{MW}$ peak reduction in following two years [39]. During 1997-2003, Beijing's DSM project focus was just to improve load factor above $80 \%$ that falls below 76\% [37], [40]. However, this focus shifted to other DR schemes like increasing the difference of peak and valley prices, involving industrial users to participate in interruptible DR schemes, increase in the usage of energy storage devices. Beijing was pioneer city that took part in DSM pilot projects of National Development and Reform Commission (NDRC) and Ministry of Finance (MoF). Being part of three year plan (2013-2015), Beijing reduce load up to $800 \mathrm{MW}$ that composed of 4 to $5 \%$ of city's entire load. List of targets of all pilot cities of three year plan are enlisted in Table VI. 
TABLE VI. PILOT DR PROGRAMS TILL 2015

\begin{tabular}{|l|l|l|l|l|}
\hline City & \multicolumn{3}{|l|}{ 2015 Load Reduction Goals (MW) } & $\begin{array}{l}\text { Targeted End } \\
\text { Users }\end{array}$ \\
\hline & $\begin{array}{l}\text { Temporary } \\
\text { reduction }\end{array}$ & $\begin{array}{l}\text { Permanent } \\
\text { reduction }\end{array}$ & $\begin{array}{l}\text { Total load } \\
\text { reduction }\end{array}$ & \\
\hline Beijing & 150 & 650 & 800 & $\begin{array}{l}\text { Commercial } \\
\text { buildings, } \\
\text { Industry and } \\
\text { Municipal } \\
\text { facilities }\end{array}$ \\
\hline Suzhou & 200 & 800 & 1000 & $\begin{array}{l}\text { Industry and } \\
\text { Municipal } \\
\text { facilities }\end{array}$ \\
\hline Foshan & 90 & 360 & 450 & $\begin{array}{l}\text { Industry and } \\
\text { Municipal } \\
\text { facilities }\end{array}$ \\
\hline Tangshan & Total load reduction-400 & Industry \\
\hline
\end{tabular}

Load reduction, less reliance on fossil fuels and achievement of $40 \%$ renewable energy generation till 2030 are the main goals of China. Investing in the latest control and communication technologies, China is making progress by implementing pilot projects across industrial provinces. However, lack of competitive market prices, reasonable incentive allotment, customer education programs and Government involvement and supervision impedes the growth of DR in China [39], [41]-[43].

\section{CONCLUSIONS AND FUTURE WORK}

DR can play a vital role in balancing the supply and demand without introducing more generation capacity and threatening environment. $100 \mathrm{GW}$ DR potential in Europe, $14 \%$ peak demand reduction using DR in USA till 2019 and 40\% RE generation by China till 2030 highlights the significance of DR across world-wide. Current developments within developed countries regarding to a wide rollout of advance metering infrastructure technology will enable the consumer for prompt action during peak hours or in case of contingency.

In spite of the effectiveness in mitigating peak demand and addressing RE integration issues there are still some barriers in using DR to its full potential. Educating customers, introduction of aggregators, competitive market price and two way communication between utility and customers need to be done. Although DR in World has not reached its entire potential, however collecting information about potential targets, proposing an action plan and educating the customers can prove successful to attract remaining energy sectors as well as industrial, commercial and residential customers.

The problem with existing DR programs is that inelastic loads like lamps, refrigerators cannot participate unless users are willing to loss of comfort. Therefore, to solve this issue, novel concept Integrated Demand Response (IDR) has been proposed recently. IDR deals with multi energy carries and provides the option of switching energy source. It guarantees all users participation without loss of comfort and can be further explored for future work.

\section{REFERENCES}

[1] Lampropoulos, I., et al. History of demand side management and classification of demand response control schemes. in 2013 IEEE Power \& Energy Society General Meeting. 2013.

[2] Joseph, H.E., The Past, Present, and Future of U.S. Utility Demand-Side Management Programs. 1996, LBNL: Berkeley.

[3] Auffhammer, M., C. Blumstein, and M. Fowlie, Demand-Side Management and Energy Efficiency Revisited. The Energy Journal, 2008. 29(3): p. 91-104.

[4] Gupta, P., Impact of Demand Side Management Programs on Peak Load Electricity Demand in North America, 1992 to 2008.

[5] Strbac, G., Demand side management: Benefits and challenges. Energy Policy, 2008. 36(12): p. 4419-4426.

[6] Palensky, P. and D. Dietrich, Demand Side Management: Demand Response, Intelligent Energy Systems, and Smart Loads. IEEE Transactions on Industrial Informatics, 2011. 7(3): p. 381-388.

[7] Gelazanskas, L. and K.A.A. Gamage, Demand side management in smart grid: A review and proposals for future direction. Sustainable Cities and Society, 2014. 11: p. 22-30.

[8] Zhao, H. and Z. Tang. The review of demand side management and load forecasting in smart grid. in 2016 12th World Congress on Intelligent Control and Automation (WCICA). 2016.

[9] Song, L., Y. Xiao, and M.v.d. Schaar, Demand Side Management in Smart Grids Using a Repeated Game Framework. IEEE Journal on Selected Areas in Communications, 2014. 32(7): p. 1412-1424.

[10] Mahmood, A., et al., A New Scheme for Demand Side Management in Future Smart Grid Networks. Procedia Computer Science, 2014. 32: p. 477-484.

[11] Solomon, S., et al., Persistence of climate changes due to a range of greenhouse gases. Proceedings of the National Academy of Sciences of the United States of America, 2010. 107(43): p. 18354-18359.

[12] Tahir, M.F., et al., Optimal Load Shedding Using an Ensemble of Artificial Neural Networks. International Journal of Electrical and Computer Engineering Systems, 2016. Volume 7, (2): p. 39-46.

[13] Tahir, M.F., H. Tehzeeb ul, and M.A. Saqib, Optimal scheduling of electrical power in energy-deficient scenarios using artificial neural network and Bootstrap aggregating. International Journal of Electrical Power \& Energy Systems, 2016. 83(Supplement C): p. 49-57.

[14] Chen, H., et al., Key Technologies for Integration of Multitype Renewable Energy Sources\&\#x2014;Research on Multi-Timeframe Robust Scheduling/Dispatch. IEEE Transactions on Smart Grid, 2016. 7(1): p. 471-480.

[15] Verzijlbergh, R.A., et al., Institutional challenges caused by the integration of renewable energy sources in the European electricity sector. Renewable and Sustainable Energy Reviews, 2017. 75: p. 660667.

[16] Boyd, P.A., G.B. Parker, and D.D. Hatley, Load Reduction, Demand Response and Energy Efficient Technologies and Strategies. 2008: United States.

[17] Bradley, P., M. Leach, and J. Torriti, A review of the costs and benefits of demand response for electricity in the UK. Energy Policy, 2013. 52: p. 312-327.

[18] Paridari, K., et al. Demand response for aggregated residential consumers with energy storage sharing. in 2015 54th IEEE Conference on Decision and Control (CDC). 2015.

[19] Liu, Y., Demand response and energy efficiency in the capacity resource procurement: Case studies of forward capacity markets in ISO New England, PJM and Great Britain. Energy Policy, 2017. 100(C): p. 271282.

[20] Goldman, C., et al., Coordination of energy efficiency and demand response. 2010, Ernest Orlando Lawrence Berkeley National Laboratory, Berkeley, CA (US).

[21] Qdr, <DOE_Benefits_of_Demand_Response_in_Electricity_Markets_and_R 
ecommendations_for_Achieving_Them_Report_to_Congress.pdf $>$. US Department of Energy, February 2006: p. 1-122.

[22] Qdr, Q., Benefits of demand response in electricity markets and recommendations for achieving them. 2006.

[23] Aalami, H.A., M.P. Moghaddam, and G.R. Yousefi, Demand response modeling considering Interruptible/Curtailable loads and capacity market programs. Applied Energy, 2010. 87(1): p. 243-250.

[24] Shayesteh, E., et al. Congestion Management using Demand Response programs in power market. in 2008 IEEE Power and Energy Society General Meeting - Conversion and Delivery of Electrical Energy in the 21 st Century. 2008.

[25] Gill, C.P.S., Y.S. Brar, and K.S. Singh. Incentive based demand response program: An effective way to tackle peaking electricity crisis. in 2012 25th IEEE Canadian Conference on Electrical and Computer Engineering (CCECE). 2012.

[26] York, D. and M. Kushler. Exploring the Relationship Between Demand Response and Energy Efficiency: A Review of Experience and Discussion of Key Issues. 2005.

[27] Ruff, L., Economic principles of demand response in electricity. 2002.

[28] Hurley, D., P. Peterson, and M. Whited, Demand response as a power system resource. 2013.

[29] Lee, M., et al., Assessment of demand response and advanced metering. Federal Energy Regulatory Commission, Tech. Rep, 2013.

[30] Cappers, P., C. Goldman, and D. Kathan, Demand response in US electricity markets: Empirical evidence. Energy, 2010. 35(4): p. 15261535 .

[31] Hamidi, V., F. Li, and F. Robinson, Demand response in the UK's domestic sector. Electric Power Systems Research, 2009. 79(12): p. $1722-1726$.
[32] Torriti, J., M.G. Hassan, and M. Leach, Demand response experience in Europe: Policies, programmes and implementation. Energy, 2010. 35(4): p. $1575-1583$.

[33] Coalition, S.E.D., Mapping demand response in Europe today. Tracking Compliance with Article, 2014. 15.

[34] Eid, C., et al., Time-based pricing and electricity demand response: Existing barriers and next steps. Utilities Policy, 2016. 40: p. 15-25.

[35] Trinomics, The Potential of Electricity Demand Response Committee on Industry, Research and Energy (ITRE) 2017: p. 1-66.

[36] Zhang, Q., et al., External costs from electricity generation of China up to 2030 in energy and abatement scenarios. Energy Policy, 2007. 35(8): p. 4295-4304.

[37] Ming, Z., et al., Historical review of demand side management in China: Management content, operation mode, results assessment and relative incentives. Renewable and Sustainable Energy Reviews, 2013. 25(Supplement C): p. 470-482

[38] Zhong, J., et al., Demand side management in China. IEEE Power and Energy Society General Meeting, 2010: p. 1-4.

[39] Wang, J., et al., Demand response in China. Energy, 2010. 35(4): p. 1592-1597.

[40] Zhao, Z., et al., Demand side management: A green way to power Beijing. Vol. 7. 2015. 041505.

[41] Dong, J., G. Xue, and R. Li, Demand response in China: Regulations, pilot projects and recommendations - A review. Renewable and Sustainable Energy Reviews, 2016. 59: p. 13-27.

[42] Guo, P., V.O.K. Li, and J.C.K. Lam, Smart demand response in China: Challenges and drivers. Energy Policy, 2017. 107: p. 1-10.

[43] Yang, C.-J., Opportunities and barriers to demand response in China Resources, Conservation and Recycling, 2017. 121: p. 51-55. 